\title{
Clinical longevity of ceramic laminate veneers bonded to teeth with and without existing composite restorations up to 40 months
}

\author{
Gresnigt, Marco M M ; Kalk, Warner ; Özcan, Mutlu
}

\begin{abstract}
OBJECTIVES: This study evaluated the survival rate of ceramic laminate veneers bonded to teeth with and without existing composite restorations (ECR). MATERIALS AND METHODS: Twenty patients (mean age: 49.7 years) received 92 feldspathic ceramic laminate veneers (Shofu Vintage AL) on the maxillary teeth (intact teeth: $n=26$; teeth with ECR: $n=66$ ). Preparations with incisal overlap were made, and ECR of good quality were not removed but conditioned using silica coating (CoJet) and silanization (ESPE-Sil). Enamel and dentin were etched with $38 \% \mathrm{H} 3 \mathrm{PO} 4$ for 15-30 s and rinsed $30 \mathrm{~s}$; adhesive resin (Excite) was applied, and laminate veneers were then cemented (Variolink Veneer). Restorations were evaluated at baseline and thereafter every 6 months using modified United States Public Health Service criteria. RESULTS: Mean observation period was 21.6 months. Overall, five absolute failures were encountered (fractures: $n=3$; chipping: $n=1$; debonding: $n=1$ ), resulting in a survival rate of $94.6 \%$ (Kaplan-Meier). Survival rates of the laminates bonded to teeth without (96\%) and with ECR (93.5\%) did not show significant differences $(p>0.05)$. Slight marginal defects (16 of 87 laminates) and slight marginal discoloration at the margins were noted (12 of 87 laminates) until the final recall. Secondary caries and endodontic complications were not detected in any of the teeth. CONCLUSION: The clinical survival of ceramic laminate veneers up to 40 months was not significantly influenced when they were bonded onto intact teeth or onto teeth with ECR. CLINICAL RELEVANCE: When no caries is present, it may not be necessary to replace existing composite restorations prior to cementation of ceramic laminate veneers.
\end{abstract}

DOI: https://doi.org/10.1007/s00784-012-0790-5

Posted at the Zurich Open Repository and Archive, University of Zurich

ZORA URL: https://doi.org/10.5167/uzh-89946

Journal Article

Accepted Version

Originally published at:

Gresnigt, Marco M M; Kalk, Warner; Özcan, Mutlu (2013). Clinical longevity of ceramic laminate veneers bonded to teeth with and without existing composite restorations up to 40 months. Clinical Oral Investigations, 17(3):823832.

DOI: https://doi.org/10.1007/s00784-012-0790-5 
Clinical longevity of ceramic laminate veneers bonded to teeth with and without existing composite restorations up to 40 months

\title{
Marco M.M. Gresnigt • Warner Kalk • Mutlu Özcan
}

\author{
M.M.M. Gresnigt* \\ University of Groningen, University Medical Center Groningen, Department of Fixed and Removable \\ Prosthodontics, Center for Dentistry and Oral Hygiene, Antonius Deusinglaan 1, 9713 AV Groningen, The \\ Netherlands. \\ e-mail: marcogresnigt@yahoo.com
}

\section{W. Kalk}

University of Groningen, University Medical Center Groningen, Department of Fixed and Removable Prosthodontics, Center for Dentistry and Oral Hygiene, Antonius Deusinglaan 1, 9713 AV Groningen, The Netherlands.

\section{M. Özcan}

University of Zürich, Dental Materials Unit, Center for Dental and Oral Medicine, Clinic for Fixed and Removable Prosthodontics and Dental Materials Science, Plattenstrasse 11, CH-8032, Zürich, Switzerland.

Short title: Laminate veneers bonded to teeth with existing restorations

*Part of this study has been presented as an oral presentation at the 89th General Session and Exhibition of the International Association for Dental Research (IADR) in San Diego, California, USA held between March, 16-19th, 2011. 


\begin{abstract}
s
Objectives This study evaluated the survival rate of ceramic laminate veneers bonded to teeth with and without existing composite restorations (ECR).

Materials and methods Twenty patients (mean age: $49.7 \mathrm{yrs}$ ) received 92 feldspathic ceramic laminate veneers (Shofu Vintage $A L$ ) on the maxillary teeth (intact teeth: $n=26$; teeth with $E C R$ : $n=66$ ). Preparations with incisal overlap were made and ECR of good quality were not removed but conditioned using silica coating (CoJet) and silanization (ESPE-Sil). Enamel and dentin were etched with $38 \% \mathrm{H}_{3} \mathrm{PO}_{4}$ for $15-30 \mathrm{~s}$, rinsed $30 \mathrm{~s}$, adhesive resin (Excite) was applied and laminate veneers were then cemented (Variolink Veneer). Restorations were evaluated at baseline and thereafter every 6 months using modified USPHS criteria.
\end{abstract}

Results Mean observation period was 21.6 months. Overall, 5 absolute failures were encountered (fractures: $n=3$; chipping: $n=1$; debonding: $n=1$ ) resulting in a survival rate of $94.6 \%$ (Kaplan-Meier). Survival rates of the laminates bonded to teeth without (96\%) and with ECR (93.5\%) did not show significant differences $(p>0.05)$. Slight marginal defects (16 of 87 laminates) and slight marginal discoloration at the margins were noted (12 of 87 laminates) until the final recall. Secondary caries and endodontic complications were not detected in any of the teeth.

Conclusion The clinical survival of ceramic laminate veneers up to 40 months was not significantly influenced when they were bonded onto intact teeth or onto teeth with ECR.

Clinical relevance When no caries is present, it may not be necessary to replace existing composite restorations prior to cementation of ceramic laminate veneers.

Keywords: Adhesion - Clinical trial - Existing restorations - Ceramic Laminate veneers - Surface conditioning 


\section{Background}

The use of ceramic laminate veneers as opposed to metal-ceramic or all-ceramic full coverage crowns, is a minimal invasive treatment option in reconstructive dentistry. Since their retention relies solely on adhesion, durable adhesion of resin luting cements to both the enamel/dentin and the cementation surface of the ceramic is crucial. Luting cements used in conjunction with phosphoric acid etching followed by adhesive application on enamel show reliable adhesion [1-3] with mean bond strengths up to $40 \mathrm{MPa}$ [4]. Also, etching the intaglio of glass ceramic veneers with hydrofluoric acid followed by silane coupling agent application delivers bond strength values similar to or higher than to enamel [5-12]. Even after long-term water storage and thermocycling aging conditions, promising results were reported with resin-ceramic adhesion $[7,9,12]$.

Ceramic laminates are indicated not only to restore malformed, malpositioned or discolored teeth where mainly the substrate is the enamel and/or dentin but also in situations where resin composite restorations are present on the tooth to be restored. In case of secondary caries, severe marginal or surface changes, it may be necessary to remove such restorations. On the other hand, degradation of polymers in the aggressive oral environment may decrease the free radicals available on the resin surface that may eventually decrease the adhesion of resin cements to such composites [13]. However, limited information is available on the survival of ceramic laminates on such existing composite restorations where mainly fractures and marginal defects were reported $[3,14]$. Defects were especially noticed at the locations where the existing fillings were present [14]. In fact, today advances in surface conditioning methods and adhesion promoters enable durable composite-composite adhesion. Among numerous other methods, several studies reported increased composite-composite bond strengths after conditioning the composites with alumina or alumina coated silica particles followed by silanization [15-18]. The process of silanization promotes the wettability of the substrates and further reacts with the glass particles present on the composite surface 
forming covalent bonds $[7,19]$. Composite-composite bond strength simulating aging after silica coating and silanization was reported to deliver significantly higher bond strengths (46-52 MPa) than conditioning the composite substrate with phosphoric acid and adhesive resin application only (16-25 MPa) [18].

Unfortunately, the previous clinical studies did not report application of any surface conditioning method prior to cementation of ceramic laminates $[3,14]$. In clinical practice, the clinical dilemma is whether or not to remove the existing composite restorations with no indications of caries or acceptable surface degradation that could be re-finished and re-polished. Alternatively, full-coverage crowns are indicated on teeth with large composite restorations that require more tissue removal yielding to preparations in dentin that is a substrate less favourable to bond onto than enamel [20-22].

The objective of this prospective clinical study was to evaluate the performance of ceramic laminate veneers bonded onto either intact teeth or to teeth with existing composite restorations with no indications of caries, ditching or marginal staining. The null hypothesis tested was that the presence of existing composite restorations would not decrease the survival rate of ceramic laminate veneers compared to those bonded onto intact teeth.

\section{Materials and methods}

\section{Patient inclusion/exclusion criteria}

Between June-2007 and October-2010, twenty consecutively recruited patients (15 female, 5 male; mean age 49.7 years old, range: $19-70$ years old) who needed indirect ceramic laminate veneer restorations and met the inclusion criteria, were included in this study. Patients recruited for this study were referred from the surrounding local general practices. Before entering the trial, all patients were provided with informed consent form approved by the ethical committee of the university institutional review board (ABR number: NL 14837.042.06). Information was given to each patient regarding the alternative treatment options. The 
inclusion criteria comprised the following: all subjects were required to be at least 18 years old, able to read and sign the informed consent document, physically and psychologically able to tolerate conventional restorative procedures, having no active periodontal or pulpal diseases, having teeth with good restorations, and willing to return for follow-up examinations as outlined by the investigators. Patients with a history of parafunctional habits were not excluded but a splint was provided after cementation of restorations. Existing composite restorations of good quality, presenting no visible caries, ditching or marginal staining were not removed prior to tooth preparation. They were rated for their size; restorations covering more than $2 / 3$ of the labial surfaces were considered as big, $2 / 3$ to $1 / 3$ of the labial surface as medium, $1 / 3$ of the surface as small restorations. Non-vital teeth were not excluded from the study.

\section{Pre-operative procedures}

Prior to treatment with ceramic laminate veneers, gingival corrections and bleaching were performed when needed. Alignment corrections were made through orthodontics where necessary. Esthetic evaluations were made using digital photographs, plaster cast models mounted on an articulator after using face-bow registrations. Shade was determined under standard conditions $(6500 \mathrm{~K}, 8$ light intensity, Longlife, Aura, The Netherlands) at the dental laboratory. A wax set-up was made on the plaster cast using the mock-up technique $[23,24]$. The set-up was used to communicate on the correction of the form and position of the teeth and also to evaluate the patient's expectations. Only after patient's approval of the mock-up, tooth preparations were made.

\section{Tooth preparation}

Magnified loops (x4.2) (Examvision, Rotterdam, The Netherlands) and a magnifying microscope (x3.4 21.3) (Opmipico, Zeiss, Sliedrecht, The Netherlands) were used for minimal preparations. Ball-shaped diamond burs (no: 676, Dentsply Maillefer, Ballaigues, Switzerland) were used to mark preparation depths 
through the set-up. The preparation depth was controlled using a silicone key made on the diagnostic waxup, taking into account that the minimal thickness of the veneer was $0.3-0.5 \mathrm{~mm}$. A shallow chamfer finish line of $0.5 \mathrm{~mm}$ was made through the mock-up. Tapered round-ended diamond chamfer burs were used for uniform preparations. A right-angled (butt joint) preparation with incisal overlap of 1-1.5 mm was achieved in all cases to attain space for translucency. At the cervical area, a shallow chamfer finish line $(0.5 \mathrm{~mm})$ was created epi- or supra-gingival to maintain good periodontal health. A light chamfered marginal finish line extended inter-proximally only to hide the restoration margins, proximal contact points of the natural teeth were maintained. Similarly, in the case of existing restorations, the laminate veneers ended in approximately half of the composite restorations in the inter-proximal area. All internal angles were smoothed to reduce stress concentration. Impressions were then made using a polyether impression material (Impregum, 3M ESPE, St. Paul, MN, USA). Temporary veneers were made chair-side using an auto-polymerized composite restorative material (Structur SC, Voco, Cuxhaven, Germany). For the fixation of the temporary veneers, enamel was spot etched with $37 \%$ phosphoric acid (Ultra-Etch, Ultradent, South Jordan, UT, USA) for 30 seconds.

\section{Adhesive cementation}

One dental technician fabricated the ceramic veneers using feldspathic material (Shofu Vintage AL, Shofu, Kyoto, Japan). The ceramic veneers were baked onto refractory die. The minimal thickness of the veneers was $0.3 \mathrm{~mm}$. The form, adaptation and shade match of the restorations were checked. The colour of the cement to be chosen was determined using try-in pastes (Variolink Veneer Try-in Paste, Ivoclar Vivadent, Schaan, Liechtenstein).

A list of materials used in this study is shown in Table 1. Sequence of adhesive procedures is presented in Tables 2a-b. After cleaning the cementation surfaces of the laminates with $99 \%$ isopropanol, they were etched with $4.9 \%$ hydrofluoric acid (IPS Ceramic etching gel, Ivoclar Vivadent) for 1 minute, 
washed thoroughly for 1 minute and dried with oil-free compressed air. Etching with hydrofluoric acid leaves a significant amount of crystalline debris precipitate at the ceramic surface ${ }^{25}$ For this reason, laminates were ultrasonically cleaned in distilled water for 5 minutes. Thereafter, the cementation surfaces were silanized (Monobond S, Ivoclar Vivadent) and waited for its reaction for 1 minute. After silanization, adhesive resin (Excite, Ivoclar Vivadent) was applied, air-thinned but not polymerized.

All teeth to be veneered were isolated using a split-rubberdam technique. Contour strips (ContourStrip, Ivoclar Vivadent) were placed with the help of wedges interproximally to perform a smooth restoration outline in the cervical area. The prepared teeth were first cleaned with fluoride-fee pumice (Pumice Flour, Dux, Utrecht, The Netherlands) using a polishing brush (Polishing brush, Coltene Whaledent, Altstatten, Switzerland).

The existing composite restorations were silica coated $\left(30 \mu \mathrm{m} \mathrm{SiO}{ }_{2}\right.$, CoJet $^{\circledR}-$ Sand, $3 M$ ESPE AG) using an intraoral air-abrasion device (Dento-Prep ${ }^{T M}$, RøNVIG A/S, Daugaard, Denmark) at a pressure of 2.5 bar from a distance of approximately $10 \mathrm{~mm}$ for 5 seconds. Then, enamel and dentin were etched with $38 \% \mathrm{H}_{3} \mathrm{PO}_{4}$ (Ultra-etch, Ultradent, South Jordan, USA) for 15-30 seconds. After rinsing for 30 seconds and air-drying, a 3-methacryloxypropyltrimethoxy silane coupling agent (MPS) (ESPE ${ }^{\circledR}-S i l, 3 M$ ESPE AG) was applied on the existing composite restorations and waited for its evaporation for 5 minutes. The adhesive resin (Excite, Ivoclar Vivadent) was then applied on both the tooth and the restoration surfaces with a microbrush for 15 seconds, air-thinned but not polymerized.

Laminates were cemented using a photo-polymerized luting cement (Variolink Veneer, Ivoclar Vivadent). Cement was applied to the inner surfaces of the laminates. After placement, initially, they were photo-polymerized (Bluephase, Ivoclar Vivadent) for only 3 seconds at the buccal surface to ensure stabilization of the veneer. The light output was at least $800 \mathrm{~mW} / \mathrm{cm}^{2}$ in all applications. Gross excess 
cement at the margins was removed immediately with the aid of brushes, scalers and dental floss (Oral-B, Rotterdam, The Netherlands).

Application of glycerine gel (Liquid-Strip, Ivoclar Vivadent) at the margins ensured oxygen inhibition during polymerization. Buccal, oral, and proximal surfaces were further polymerized for $40 \mathrm{~s}$ each. After rinsing the glycerine gel, excess cement was removed with hand-instruments and finishing burs. Restoration margins were further polished with silicone polishers (Astropol FP, HP, Ivoclar Vivadent) and interproximal polishing strips (Soft-Lex Finishing Strips, 3M ESPE) at 7.500-10.000 rpm under water. One clinician (M.G.) placed the restorations. Finally, the occlusion was checked in protrusive movements of the mandible. The time spent for the restoration was also recorded at the end of each session.

\section{Evaluation}

Restorations were evaluated at baseline and thereafter every 6 months by two calibrated observers who were blinded to the objective of this study. Caries, debonding, chipping and fracture were considered as absolute failures. Patients were also questioned about possible post-operative complaints. Both observers evaluated the restorations independently, according to the modified United States Public Health Service (USPHS) criteria (Table 3). The restorations were visually inspected with dental mirror and probe. After data collection, in case of discrepancies in scoring, restorations were evaluated again, a consensus was reached and this was accepted as the final score. Patients were instructed to call upon any kind of failure. Digital photographs were made after placement of the veneers and during follow-up sessions.

\section{Statistical analysis}

Survival analyses were performed with statistical software program (SPSS 13.0; SPSS Inc, Chicago, IL, USA) using Kaplan-Meier and Log Rank (Mantel-Cox) tests to obtain the cumulative survival rates in relation to observation time. $P$ values less than 0.05 were considered to be statistically significant in all 
tests. Power analysis was performed using a statistical software package (Stata, StataCorp, Texas, USA) for two-sample comparison of survival functions (Log-rank, Freedman).

\section{Results}

In total, 5 recalls were performed after baseline measurements and no drop-out was experienced yielding to the evaluation of 92 ceramic laminate veneers. The mean observation time was 21.6 months with a minimum observation period of 7 months and maximum 40 months. Of these 92 laminate veneers, 26 veneers were cemented onto intact teeth, 66 veneers were cemented onto teeth with existing composite restorations of which 62 veneers had their margins in the composite. The distribution of their locations in the maxilla was as follows: 35 on central incisors, 36 on lateral incisors, and 21 on canines. Of the 66 laminate veneers bonded onto teeth with existing restorations, 7 were big, 17 medium, and 42 small restorations. Ten of the existing restorations were Class III, 52 of them were Class IV and 4 of them were Class V restorations. Of all teeth, 27 had no visual dentin exposure, 13 teeth had more than 50 percent dentin exposure and 50 laminates were placed on teeth without margins in the dentin. Average treatment time for each restoration was noted to be approximately 130 minutes. Three patients received occlusal splints after cementation.

Overall, survival rate was $94.6 \%$ (Kaplan-Meier). The survival rates of the ceramic laminates bonded to teeth without $(96.0 \%)$ and with existing resin composite restorations (93.5\%) did not show significant differences $(p>0.05)$ [Kaplan-Meier, Log Rank (Mantel-Cox) $(\mathrm{Cl}=95 \%)$ ] (Fig. 1). Also, the size of the existing composite did not significantly affect the survival rate $(p>0.05)$. The power of the study was calculated to be $97 \%$.

A total of 5 absolute failures were observed in the form of debonding ( $n=1)$ (Fig. 2a), chipping $(n=1)$ (Fig. 2b) and fractures ( $n=3)$ (Fig. 2c-e). Three months after cementation, one laminate debonded with an adhesive failure between the tooth and the luting cement. On both mesial and distal sides of the tooth (12) 
there were small existing composite restorations. After cleaning the cementation surface, the debonded veneer was re-cemented using the same adhesive protocol (Table 2a-b).

The chipping was a cohesive failure in the ceramic at the incisal edge that occurred 18 months after cementation (Fig. 2b). The laminate veneer was bonded onto tooth 23 that had no existing restorations. It was replaced with a new laminate veneer of the same kind. Eight months after placement, one of the fractures occurred at the cervical area of a laminate veneer on tooth 21 that had big existing composite restorations on the mesial and distal sides (Fig. 2c). The detached fragment was debonded in an adhesive fashion with no luting cement bonded to dentin. Patient reported that he bit on a cherry seed. The second laminate fracture was experienced on tooth 12,38 months after cementation (Fig. 2d). It was fractured into two pieces. While one half was left attached on an existing composite restoration on the mesial side of the tooth, the other half was debonded adhesively from the dentin surface. The third laminate fracture presented itself with crack lines on tooth 11 with an existing restoration at the mesial side, 4 months after cementation (Fig. 2e). All 5 failures were experienced in laminate veneers bonded to vital teeth.

Slight marginal defects on 16 of 87 laminates (USPHS criteria, Adaptation-Score 1) and slight marginal discoloration were noted on 12 of 87 laminates (USPHS criteria, Marginal discoloration-Scores 1 and 2) until the final recall (Table 4). Secondary caries, endodontic complications or wear of the antagonist were not observed in any of the cases.

In total 20 teeth showed post-operative sensitivity at baseline. Eighteen of them disappeared after 2 weeks. The other two cases showed slight sensitivity to cold beverages after 22 and 24 months, respectively but patients did not want any intervention. 


\section{Discussion}

This prospective clinical study evaluated the performance of ceramic laminate veneers bonded onto maxillary teeth with and without existing composite restorations. Since the survival rates of the ceramic laminates bonded to teeth without (96\%) and with existing resin composite restorations (93.5\%) did not show significant differences, the hypothesis could be accepted. The results obtained after a relatively short follow-up period of time, with mean observation period of 21.6 months, should be evaluated with caution. Overall, $94.6 \%$ of the restorations required no intervention until the final follow up, which could be considered clinically acceptable. However, early failures observed in this study could be helpful in understanding possible failure mechanisms. In previous studies, ceramic laminate veneers (IPS Empress) showed survival rates of $97 \%$ [26] and $94 \%$ [3] after 5 and 12 years, respectively where preparation margins were in enamel. Survival rates based on 10year results presented overall survival rate of $90 \%$ [14]. The most common failure type was reported to be fractures. Similar to these studies the number of absolute failures in our study is limited: 3 fractures and 1 chipping.

Different factors are responsible for crack development in all-ceramic restorations of all forms. The greatest shortcoming of ceramic materials is their low ductility that is an inherent problem yielding to crack formation [27]. Also, polymerization shrinkage of the luting composite may create stress concentrations at the adhesive interface [28] or failures may occur simply due to heavy occlusion. In one of the fractures, crack lines were visible but the ceramics were cohesively fractured without detachment from the tooth or the resin composite surface. Such a failure was observed after 4 months. In a retrospective clinical study, Dumfahrt et al. detected multiple cracklines in the feldspathic ceramic veneers after 10 years of service [1]. In another study, fractures and chippings were observed after 5 years of insertion even when a stronger ceramic material (IPS Empress) was used than the feldspathic ceramic [26]. Although a standardized preparation 
technique was used, the thickness of adhesive cement layer and ceramic thickness itself, being minimum 0.3 $\mathrm{mm}$, might have showed variations that played roles in such crack development observed in this study [2,14]. However, early cracks as in this clinical study could not be considered fatigue related failures.

In earlier studies, strong lateral extrusion contact on the laminate veneer due to canine guidance was held responsible for overloading and fracture of such restorations [1,14]. Two of the 4 fractures were caused by trauma as reported by the patients in this study, which could not be attributed to any occlusion related problem. The actual reasons for fractures or debondings remain multifactorial. After preparation, the tooth substrate composition may involve a combination of enamel, dentin and existing composite restoration which may make the adhesion more challenging. Whether the use of a 3-step etch-and-rinse adhesive would deliver better survival of such restorations as opposed to the use of a 2-step self-etch one needs further investigation. Especially in trauma related failures, it is very difficult to attribute the failure reason solely to the inferior adhesion to dentin. When the veneer is bonded to a dentin surface with a lower rigidity, the veneers may be more exposed to stresses during loading, leading to an increased risk of fractures compared to veneers bonded to enamel. Considering that only 13 teeth presented more than $50 \%$ dentin exposure and that 50 laminates were placed on teeth without margins in the dentin, long term observations should particularly concentrate on the prognosis of the laminate veneers bonded on dentin. On the other hand, the chipping failure was observed at the incisal area that could be due to thin parts of the ceramic [1]. Regarding to the fracture incidence at the cervical area, principally, in the gingival one third of a veneer preparation, dentin will be exposed due to a thin layer of enamel present at this site [4]. In that respect, the preparation and cementation procedures become more critical because high failure rates in veneers have been associated to largely exposed dentin surfaces $[1,2]$. 
Immediate dentin sealing with an adhesive prior to impression taking was not practiced in this study. In future studies it is of importance to study whether immediate dentin sealing increases adhesion of luting cements to dentin and decrease the incidence of post-operative sensitivity. It should also be noted that the amount of exposed dentin varies in each case. In situations with less dentin exposure, which is anyway controlled by the naked eye and especially by observing the frosty appearance after etching, this approach may not be necessary in situations with less dentin exposure. In 20 teeth post-operative sensitivity was present at baseline where 18 of them disappeared after 2 weeks. Not all teeth that had dentin exposure showed sensitivity. But again, the presence of dentin or enamel was solely visually determined. There were also sensitive teeth where tooth preparation was in enamel. Therefore, there was no clear correlation between the existence of high amount of sensitivities and the preparations being in dentin. Presumably, the pain threshold of the individual played a role for describing sensitivity.

While the fracture of laminate veneers could not be attributed to one single reason only, adhesive debonding failure type with no remnants of cement left on the tooth surface could be considered as a consequence of lack of sufficient adhesion. In this study, a dual-polymerized single bottle type of adhesive resin was used. Such adhesives presented comparable favorable results on enamel and dentin $[29,30]$. However, after tooth preparation, the substrate tooth surface may still contain some amounts of enamel and dentin at the same time. In the debonded case, a small resin composite was present at the mesial and distal surfaces of the tooth. Thus, the majority of the bonded substrate was tooth surface. After cleaning the cementation surface and reconditioning the laminate according to the adhesive protocol described, it was rebonded and remained functional without any problems until the end of the observation period.

Four of the 5 absolute failures experienced with laminate veneers in this study were bonded onto existing restorations. Considering that two of the fractures on existing restorations occurred due to trauma, 
and due to the insignificant differences between the groups, it cannot be stated whether the conditioning protocol employed has benefits as reported in in-vitro studies [15-18]. It should also be noted that the age and the type of the existing composite restorations are almost impossible to know when these restorations are referred from other practices. Therefore, a conditioning method was chosen that could offset the importance of the underlying composite properties [15-18]. Nevertheless, hydrolytic stability of the luting cement-composite adhesion could only be verified after long-term observations.

In a similar clinical study, where the size of the restorations was not mentioned, ceramic laminate veneers crossing existing composite restorations showed more failures than the veneers that were cemented on intact teeth, after 18 months of observation [31]. However, information on the conditioning of the composite surfaces was not mentioned. The follow-up period in the present study is slightly longer than in this latter study with similar outcome. Yet, a direct comparison could not be made due to the variations in materials used. In the present study, small existing resin composite restorations (42 out of 66) were more frequent than medium (17) and big (7) restorations. Due to the relatively small number of failures, the size of the existing composites did not significantly affect the results.

In clinical studies, absolute failures should also be coupled with the relative failures. Mainly slight marginal defects (16 of 87 laminates, USPHS criteria, Adaptation-Score 1) and slight marginal discoloration were noted (12 of 87 laminates, USPHS criteria, Marginal discoloration-Scores 1 and 2) until the final recall. Slight marginal defects on existing composite restorations (14 out of 16 ) were more common than those bonded to intact teeth (2 out of 16). It must however be noted that such defects were not always at the interface between the laminate and the restorations but also at the tooth-laminate interfaces. In previous studies, marginal defects were especially noticed at locations where the veneers ended in existing composite restorations [14,32]. However, in those clinical studies, no additional pretreatment of the existing composites other than the adhesive resin corresponding to the luting cement was used. Since the preparation margins 
were extended to the proximal sites in this study, the margins at these areas were hidden and could not be evaluated. Thus, minor voids, defects and marginal staining were mainly observed at the incisal edges only from the lingual aspect. Since in these regions, function play a significant role compared to labial surfaces, aging of the adhesive resin or the luting cement, cement wash-out or initial polymerization shrinkage may be responsible from such deteriorations and eventually staining [14]. The extension of the preparation lingually at the incisal one third did not make such minor defects or staining visible for the patients. Such adaptation defects were reported to increase from $1.2 \%$ at 6 years to $7.9 \%$ after 12 years $[3,33]$. With this kind of preparation and overlapped laminate veneers, previous clinical studies reported minimal cohesive fractures in the form of chipping at the incisal edge or palatal overlap that was attributed to functional stress concentrations [14,33]. However, no such chipping was noticed in this study. The existing composite restorations were conditioned using silica coating and silanization. One could suspect that the remnants of the particles could diminish the marginal quality, thereby decrease the adhesion of the laminate veneers. Since minor voids, defects and marginal staining were mainly observed at the lingual incisal edges, we assume that the functional stresses were more dominant in such qualitative failures. Cross-contamination of the nanometer thick silane layer with the adhesive resin may impair adhesion. Since no early failures were experienced in this clinical study, such a cross-contamination effect may be negligible. This aspect of adhesion for veneer cementation on existing restorations surrounded with enamel and dentin needs to be studied.

Today, with the adhesive methods based on various conditioning methods failures in the form of small chippings or slight marginal deteriorations could be repaired and slight marginal discoloration could be repolished. Therefore, such scores could still be considered clinically acceptable. Nonetheless, restorations are being followed-up for a longer duration. 
In this study, slight marginal defects and slight marginal discolorations were not considered as definitive failures since they had more to do with the appearance of the laminate veneer and could be easily repolished or repaired. As the patients themselves did not notice them, no intervention was required at the final observation timepoint. Nonetheless, restorations are being followed-up for a longer duration and such relative failures may require intervention affecting the success rate.

\section{Conclusions and clinical relevance}

The clinical survival of ceramic laminate veneers up to 40 months was not significantly influenced when they were bonded onto intact teeth or onto teeth with existing restorations with the protocol applied. Replacement of existing composites may not be necessary prior to the cementation of ceramic laminate veneers as long as caries is not present.

\section{Acknowledgement}

The authors acknowledge Mr. Stephan van der Made from Kwalident Dental Laboratory for the construction of ceramic laminate veneers. The authors did not have any commercial interest in any of the materials used in this study.

Conflict of interest The authors declare that they have no conflict of interest. 


\section{References}

1. Dumfahrt H, Schäffer H (2000) Porcelain laminate veneers. A retrospective evaluation after 1 to 10 years of service: Part II- clinical results. Int J Prosthodont 13:9-18.

2. Peumans M, Meerbeek van B, Lambrechts $P$, Vanherle G (2000) Porcelain veneers: a review of the literature. J Dent 28:163-177.

3. Fradeani M, Redemagni M, Corrado M (2005) Porcelain laminate veneers: 6- to 12- year clinical evaluation- a retrospective study. Int J Periodontics Restorative Dent 25:9-17.

4. Munck de J, Landuyt van K, Peumans M, Poitevin A, Lambrechts P, Braem M, van Meerbeek B (2005) A critical review of the durability of adhesion to tooth tissue: methods and results. J Dent Res 84:118-132.

5. Calamia JR (1983) Etched porcelain facial veneers: a new treatment modality based on scientific and clinical evidence. New York J Dent 53:255-259.

6. Horn HR (1983) Porcelain laminate veneers bonded to etched enamel. Dent Clin North Am 27:671-684.

7. Blatz MB, Sadan A, Kern M (2003) Resin-ceramic bonding: a review of the literature. J Prosthet Dent 3:268-274.

8. Özcan M, Vallittu PK (2003) Effect of surface conditioning methods on the bond strength of luting cement to ceramics. Dent Mater 19:725-731.

9. Blatz MB, Sadan A, Maltezos C, Blatz U, Mercante D, Burgess JO (2004) In vitro durability of the resin bond to feldspathic ceramics. Am J Dent 17:169-172.

10. Piwowarczyk A, Lauer HC, Sorensen JA (2004) In vitro shear bond strength of cementing agents to fixed prosthodontic restorative materials. J Prosthet Dent 92:265-273.

11. Nagai T, Kawamoto $Y$, Kakehashi $Y$, Matsumura H (2005) Adhesive bonding of a lithium disilicate ceramic material with resin-based luting agents. J Oral Rehabil 32:598-605. 
12. Brentel AS, Özcan M, Valandro LF, Alarça LG, Amaral R, Bottino MA (2007) Microtensile bond strength of a resin cement to feldspatic ceramic after different etching and silanization regimens in dry and aged conditions. Dent Mater 23:1323-1331.

13. Drummond JL (2008) Degradation, fatigue, and failure of resin dental composite materials. J Dent Res 87:710-719.

14. Peumans M, Munck de J, Fieuws S, Lambrechts P, Vanherle G, Van Meerbeek B (2004) A prospective ten-year clinical trial of porcelain veneers. J Adhes Dent 6:65-76.

15. Özcan M (2002) The use of chairside silica coating for different dental applications: a clinical report. J Prosthet Dent 87:469-472.

16. Trajtenberg CP, Powers JM (2004) Bond strengths of repaired laboratory composites using three surface treatments and three primers. Am J Dent 17:123-126.

17. Özcan M, Alander P, Vallittu PK, Huysmans MC, Kalk W (2005) Effect of three surface conditioning methods to improve bond strength of particulate filler resin composites. J Mater Sci: Mater in Med 16:21-27

18. Özcan M, Barbosa SH, Melo RM, Galhano GAP, Bottino MA (2007) Effect of surface conditioning methods on the microtensile bond strength of resin composite to composite after aging conditions. Dent Mater 23:1276-1282.

19. Matinlinna JP, Lassila LVJ, Vallitu PK (2006) Evaluation of five dental silanes on bonding a luting cement onto silica-coated titanium. J Dent 34:721-726.

20. Kramer N, Lohbauer U, Frankenberger R (2000) Adhesive luting of indirect restorations. Am J Dent 13:60-76.

21. Breschi L, Mazzoni A, Ruggeri A, Cadenaro M, Di Lenarda R, De Stefano Dorigo E (2008) Dental adhesion review: Aging and stability of the bonded interface. Dent Mater 24:90-101. 
22. Perdigão J (2010) Dentin bonding-Variables related to the clinical situation and the substrate treatment. Dent Mater 26:e24-37.

23. Gürel G (2003) Predictable, precise, and repeatable tooth preparation for porcelain laminate veneers. Pract Proced Aesthet Dent 15:17-24.

24. Magne $P$, Belser UC (2004) Novel porcelain laminate preparation approach driven by a diagnostic mockup. J Esthet Restor Dent 16:7-16.

25. Magne P, Cascione D (2006) Influence of post-etching cleaning and connecting porcelain on the microtensile bond strength of composite resin to feldspathic porcelain. J Prosthet Dent 96:354-361.

26. Guess P, Stappert CFJ (2008) Midterm results of a 5-year prospective clinical investigation of extended ceramic veneers. Dent Mater 24:804-813.

27. Baran G, Boberick K, McCool J (2001) Fatigue of restorative materials. Crit Rev Oral Biol Med 12:350360.

28. Peumans M, Van Meerbeek B, Yoshida Y, Lambrechts P, Vanherle G (1999) Porcelain veneers bonded to tooth structure: an ultra-morphological FE-SEM examination of the adhesive interface. Dent Mater 15:105119.

29. Ernest CP, Holzmeier M, Willershausen B (2004) In vitro shear bond strength of self-etching adhesives in comparison to 4th and 5th generation adhesives. J Adhes Dent 6:293-299.

30. Goracci C, Sadek FT, Monticelli F, Cardoso PE, Ferrari M (2004) Microtensile bond strength of selfetching adhesives to enamel and dentin. J Adhes Dent 6:313-319.

31. Karlsson S, Landahl I, Stegersjo G, Milleding P (1992) A clinical evaluation of ceramic laminate veneers. Int J Prosthodont 5:447-451.

32. Dunne SM, Millar J (1993) A longitudinal study of the clinical performance of porcelain veneers. Br Dent J $175: 317-321$ 
33. Fradeani M (1998) Six-year follow-up with Empress veneers. Int J Periodontics Restorative Dent 18:216225. 


\section{Captions to tables and figures:}

\section{Tables}

Table 1 List of materials used in this study

Table 2a-b a) Sequence of conditioning protocol of the tooth/restoration, b) The sequence of conditioning and application protocol for the ceramic laminate veneers

Table 3 List of modified United States Public Health Service (USPHS) criteria used for the clinical evaluations of the restorations

Table 4 Summaries of USPHS evaluations at baseline and final follow-up

\section{Figures}

Fig. 1 Event-free survival rates of ceramic laminate veneers based on the substrate. They were bonded onto (intact tooth without composite restorations: $96.0 \% ; n=25$, events $n=1$; with existing restorations: $93.5 \%$; $n=62$ events $n=4)$

Figs 2a-e Representative photos of some failures a) adhesively debonded laminate from tooth 12 . Note that no resin cement was bonded on the tooth that had small existing resin composites on mesial and distal sides, b) cohesive chipping of the laminate at the incisal edge of the ceramic on tooth 23 that was bonded to tooth only, c) cervical fractures of the laminate veneer on tooth 21 . It was bonded to big existing composite restorations on the mesial and distal sides of the tooth. The detached fragment was adhesively debonded with no resin cement bonded on the tooth, d) fracture of the laminate veneer on tooth 12 due to trauma that failed adhesively between the tooth and the luting cement and partially cohesively within the ceramic. Part of the ceramic laminate was left adhered where an existing composite was present and the other part was debonded from the dentin surface, e) multiple cracklines visible before fracture on laminate veneer bonded to tooth 11 without any existing restorations 


\section{Tables:}

\begin{tabular}{|c|c|c|c|c|}
\hline Brand name & Type & Manufacturer & Chemical composition & $\begin{array}{l}\text { Batch } \\
\text { number }\end{array}$ \\
\hline $\begin{array}{l}\text { Shofu } \\
\text { Vintage AL }\end{array}$ & $\begin{array}{l}\text { Feldspathic } \\
\text { ceramic }\end{array}$ & Shofu, Kyoto, Japan & $\mathrm{SiO}_{2}, \mathrm{Al}_{2} \mathrm{O}_{3}, \mathrm{~K}_{2} \mathrm{O}, \mathrm{Na}_{2} \mathrm{O}, \mathrm{CaO}, \mathrm{B}_{2} \mathrm{O}_{3}$ & 060404 \\
\hline $\begin{array}{l}\text { Variolink } \\
\text { Veneer }\end{array}$ & $\begin{array}{l}\text { Photo- } \\
\text { polymerized } \\
\text { luting cement }\end{array}$ & $\begin{array}{lc}\text { Ivoclar } & \text { Vivadent, } \\
\text { Schaan, Liechtenstein }\end{array}$ & $\begin{array}{l}\text { Urethane dimethacrylate, inorganic } \\
\text { fillers, } \\
\text { ytterberiumtrifluoride, initiators, } \\
\text { stabilizers, pigments }\end{array}$ & L26396 \\
\hline CoJet $^{(}$-Sand & Sand & $\begin{array}{l}\text { 3M ESPE AG, Seefeld, } \\
\text { Germany }\end{array}$ & $\begin{array}{l}\text { Aluminium trioxide particles coated } \\
\text { with silica, particle size: } 30 \mu \mathrm{m}\end{array}$ & 433719 \\
\hline $\mathrm{ESPE}^{\circledR}$-Sil & $\begin{array}{l}\text { Silane } \\
\text { coupling } \\
\text { agent }\end{array}$ & $\begin{array}{l}\text { 3M ESPE AG, Seefeld, } \\
\text { Germany }\end{array}$ & $\begin{array}{l}\text { Ethyl alcohol, } \\
\text { 3- } \\
\text { methacryloxypropyltrimethoxysilane, } \\
\text { ethanol }\end{array}$ & 424203 \\
\hline $\begin{array}{l}\text { Ceramic } \\
\text { Etching Gel }\end{array}$ & $\begin{array}{l}\text { Hydrofluoric } \\
\text { acid }\end{array}$ & $\begin{array}{l}\text { Ivoclar Vivadent, } \\
\text { Schaan, Liechtenstein }\end{array}$ & $<5 \%$ Hydrofluoric acid & P16134 \\
\hline Monobond S & $\begin{array}{l}\text { Silane coupling } \\
\text { agent }\end{array}$ & $\begin{array}{l}\text { Ivoclar Vivadent, } \\
\text { Schaan, Liechtenstein }\end{array}$ & $\begin{array}{l}\text { 3- } \\
\text { methacryloxypropyltrimethoxysilane, } \\
50-52 \% \text { ethanol }\end{array}$ & L36680 \\
\hline Excite & Adhesive resin & $\begin{array}{l}\text { Ivoclar Vivadent, } \\
\text { Schaan, Liechtenstein }\end{array}$ & $\begin{array}{l}\text { Dimethacrylates, alcohol, } \\
\text { phosphonic acid acrylate, } \\
\text { HEMA, } \mathrm{SiO}_{2}, \quad \text { initiators } \\
\text { stabilizers }\end{array}$ & M12980 \\
\hline Ultra-Etch & $\begin{array}{l}\text { Phosphoric } \\
\text { acid }\end{array}$ & $\begin{array}{l}\text { Ultradent Products Inc, } \\
\text { South Jordan, USA }\end{array}$ & $38 \%$ phosphoric acid & L25065 \\
\hline
\end{tabular}

Table 1 List of materials used in this study 


\begin{tabular}{|c|c|}
\hline & Sequence of Conditioning the Tooth/Restoration \\
\hline 1 & Cleaning the tooth/restoration surface with fluoride-free pumice \\
\hline 2 & Silica coating the existing composite restorations (5 s) \\
\hline 3 & Acid etching enamel (30 s) and dentin (10-15 s) $\left(38 \% \mathrm{H}_{3} \mathrm{PO}_{4}\right)$ \\
\hline 4 & Rinsing $30 \mathrm{~s}$ \\
\hline 5 & Silane (ESPE-Sil) application on the existing restorations (5 min) \\
\hline 6 & Adhesive resin (Excite) application and air-thinning \\
\hline 7 & No photo-polymerization \\
\hline 8 & Placing the laminate \\
\hline
\end{tabular}

a)

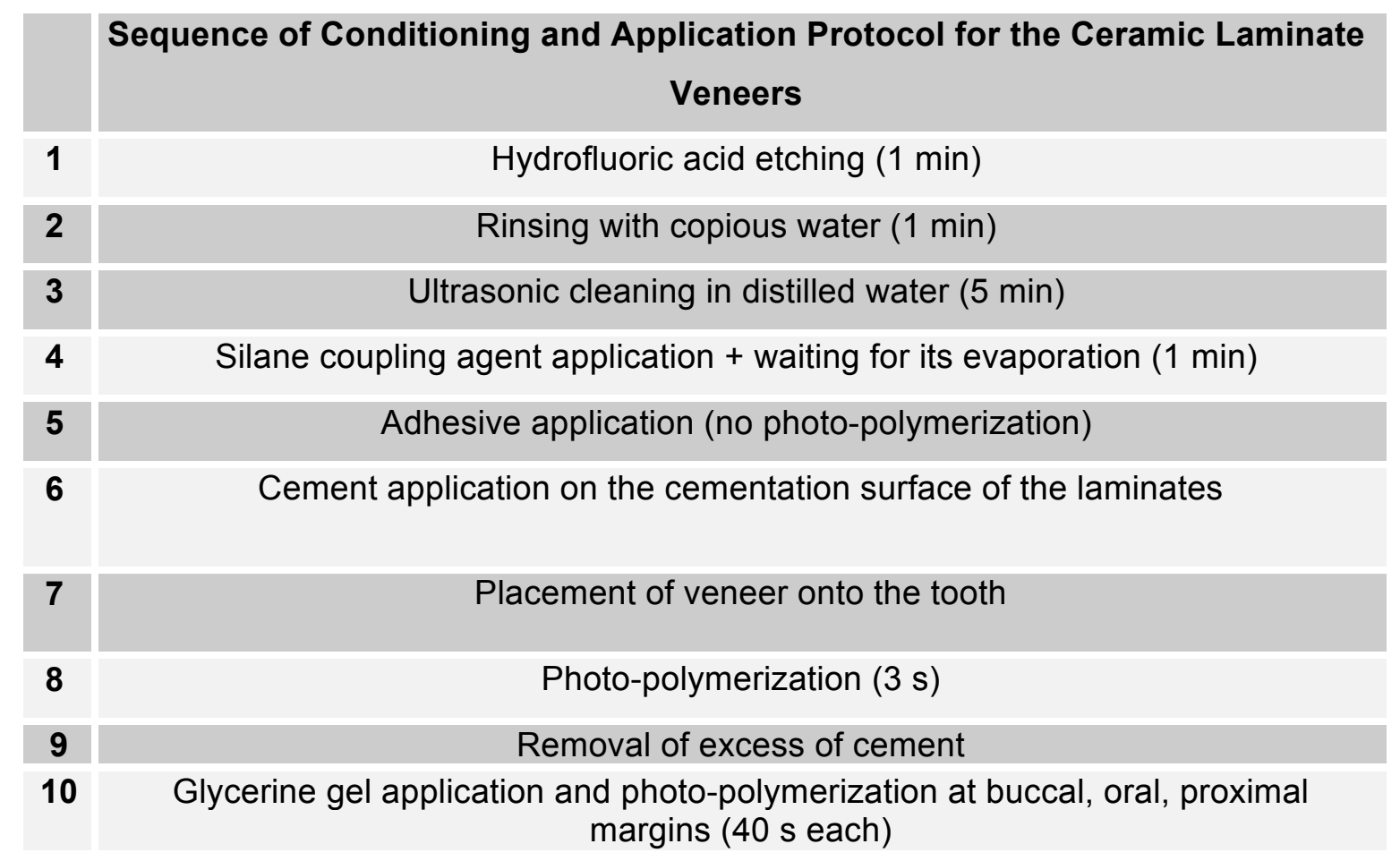

b)

Table 2a-b a) The sequence of conditioning protocol of the tooth/restoration, b) The sequence of conditioning and application protocol for the ceramic laminate veneer 


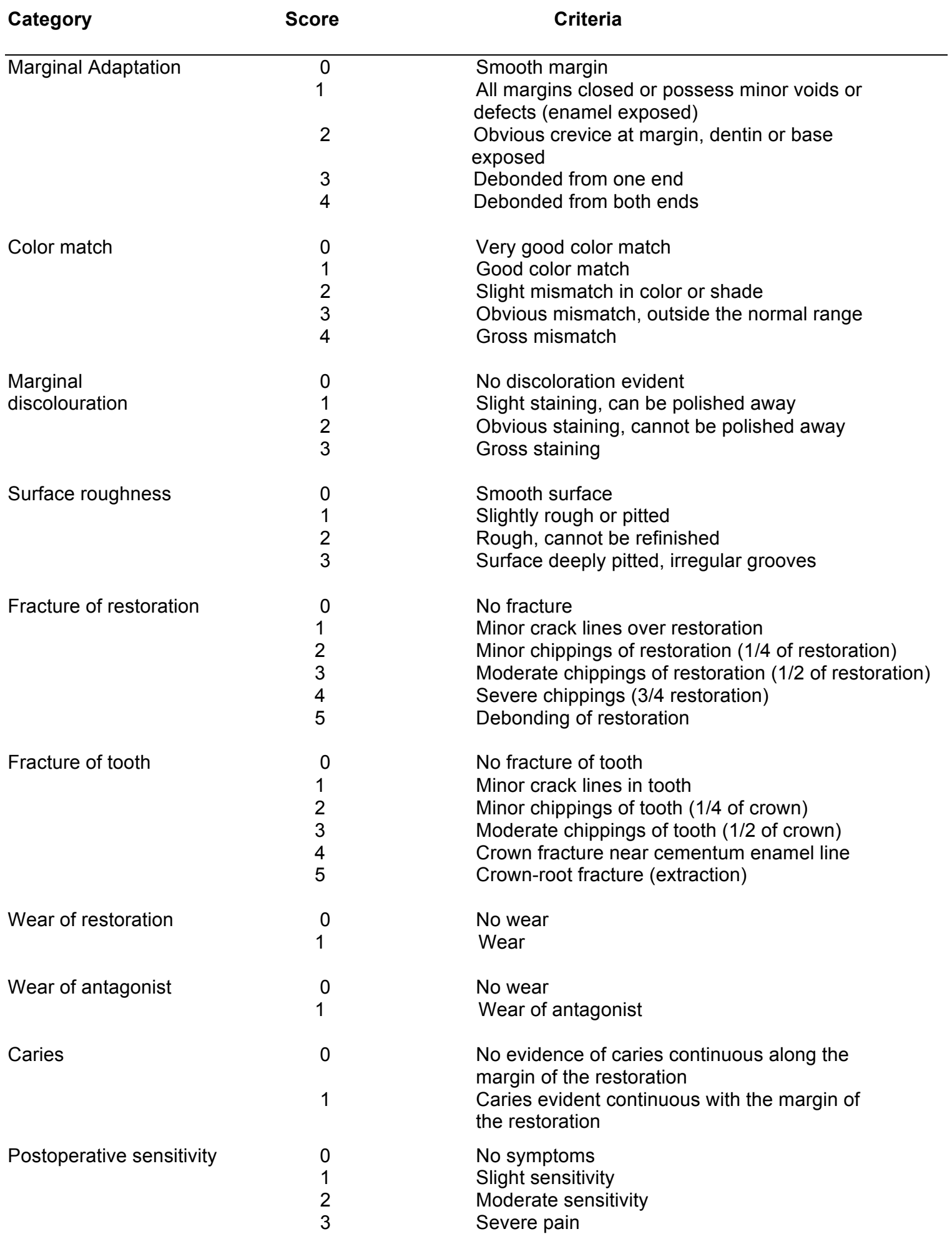


Table 3 List of modified United States Public Health Service (USPHS) criteria used for the clinical evaluations of the restorations

\begin{tabular}{|c|c|c|c|c|c|}
\hline \multirow{2}{*}{\multicolumn{2}{|c|}{ Criteria }} & \multicolumn{2}{|l|}{ Baseline } & \multicolumn{2}{|l|}{ Final Recall } \\
\hline & & $\begin{array}{l}\text { Without Restorations } \\
(n=26)\end{array}$ & $\begin{array}{l}\text { With Restorations } \\
(n=66)\end{array}$ & $\begin{array}{l}\text { Without Restorations } \\
(n=25)\end{array}$ & $\begin{array}{l}\text { With Restorations } \\
(n=62)\end{array}$ \\
\hline $\begin{array}{l}\text { Marginal } \\
\text { Adaptation }\end{array}$ & $\begin{array}{l}0 \\
1 \\
2 \\
3 \\
4\end{array}$ & $\begin{array}{l}26 \\
- \\
- \\
- \\
-\end{array}$ & $\begin{array}{l}66 \\
- \\
- \\
- \\
-\end{array}$ & $\begin{array}{l}23 \\
2 \\
- \\
- \\
-\end{array}$ & $\begin{array}{l}48 \\
14 \\
- \\
- \\
-\end{array}$ \\
\hline Color Match & $\begin{array}{l}0 \\
1 \\
2 \\
3 \\
4\end{array}$ & $\begin{array}{l}26 \\
- \\
- \\
- \\
-\end{array}$ & $\begin{array}{l}66 \\
- \\
- \\
- \\
-\end{array}$ & $\begin{array}{l}25 \\
- \\
- \\
- \\
-\end{array}$ & $\begin{array}{l}61 \\
1 \\
- \\
- \\
-\end{array}$ \\
\hline $\begin{array}{l}\text { Marginal } \\
\text { Discoloration }\end{array}$ & $\begin{array}{l}0 \\
1 \\
2 \\
3\end{array}$ & $\begin{array}{l}26 \\
-- \\
-\end{array}$ & $\begin{array}{l}66 \\
-- \\
-\end{array}$ & $\begin{array}{l}20 \\
5 \\
- \\
-\end{array}$ & $\begin{array}{l}55 \\
6 \\
1 \\
-\end{array}$ \\
\hline $\begin{array}{l}\text { Surface } \\
\text { Roughness }\end{array}$ & $\begin{array}{l}0 \\
0 \\
1 \\
2 \\
3\end{array}$ & $\begin{array}{l}- \\
26 \\
- \\
-\end{array}$ & $\begin{array}{l}- \\
66 \\
- \\
- \\
-\end{array}$ & $\begin{array}{l}- \\
25 \\
- \\
-\end{array}$ & $\begin{array}{l}- \\
62 \\
- \\
-\end{array}$ \\
\hline $\begin{array}{l}\text { Fracture of } \\
\text { Restoration }\end{array}$ & $\begin{array}{l}0 \\
1 \\
2 \\
3 \\
4 \\
5\end{array}$ & $\begin{array}{l}26 \\
- \\
- \\
- \\
- \\
-\end{array}$ & $\begin{array}{l}66 \\
- \\
- \\
- \\
- \\
-\end{array}$ & \begin{tabular}{l|}
24 \\
- \\
- \\
- \\
- \\
-
\end{tabular} & $\begin{array}{l}59 \\
- \\
- \\
- \\
- \\
-\end{array}$ \\
\hline Fracture of Tooth & $\begin{array}{l}0 \\
1 \\
2 \\
3 \\
4 \\
5\end{array}$ & $\begin{array}{l}26 \\
- \\
- \\
- \\
- \\
-\end{array}$ & $\begin{array}{l}66 \\
- \\
- \\
- \\
- \\
-\end{array}$ & $\begin{array}{l}26 \\
- \\
- \\
- \\
- \\
-\end{array}$ & $\begin{array}{l}62 \\
- \\
- \\
- \\
- \\
-\end{array}$ \\
\hline $\begin{array}{l}\text { Wear of } \\
\text { Restoration }\end{array}$ & $\begin{array}{l}0 \\
1\end{array}$ & 26 & 66 & 26 & 62 \\
\hline Wear of Antagonist & $\begin{array}{l}0 \\
1\end{array}$ & 26 & $\begin{array}{l}66 \\
-\end{array}$ & 26 & $\begin{array}{l}62 \\
-\end{array}$ \\
\hline Caries & $\begin{array}{l}0 \\
1\end{array}$ & 26 & $\begin{array}{l}66 \\
-\end{array}$ & 26 & $\begin{array}{l}62 \\
-\end{array}$ \\
\hline $\begin{array}{l}\text { Post-operative } \\
\text { Sensitivity }\end{array}$ & $\begin{array}{l}1 \\
0 \\
1 \\
2 \\
3\end{array}$ & $\begin{array}{l}26 \\
- \\
- \\
-\end{array}$ & \begin{tabular}{|l|}
66 \\
- \\
- \\
-
\end{tabular} & \begin{tabular}{|l|}
26 \\
- \\
- \\
- \\
\end{tabular} & $\begin{array}{l}60 \\
2 \\
- \\
-\end{array}$ \\
\hline
\end{tabular}

Table 4 Summaries of USPHS evaluations at baseline and final follow-up 


\section{Figures:}

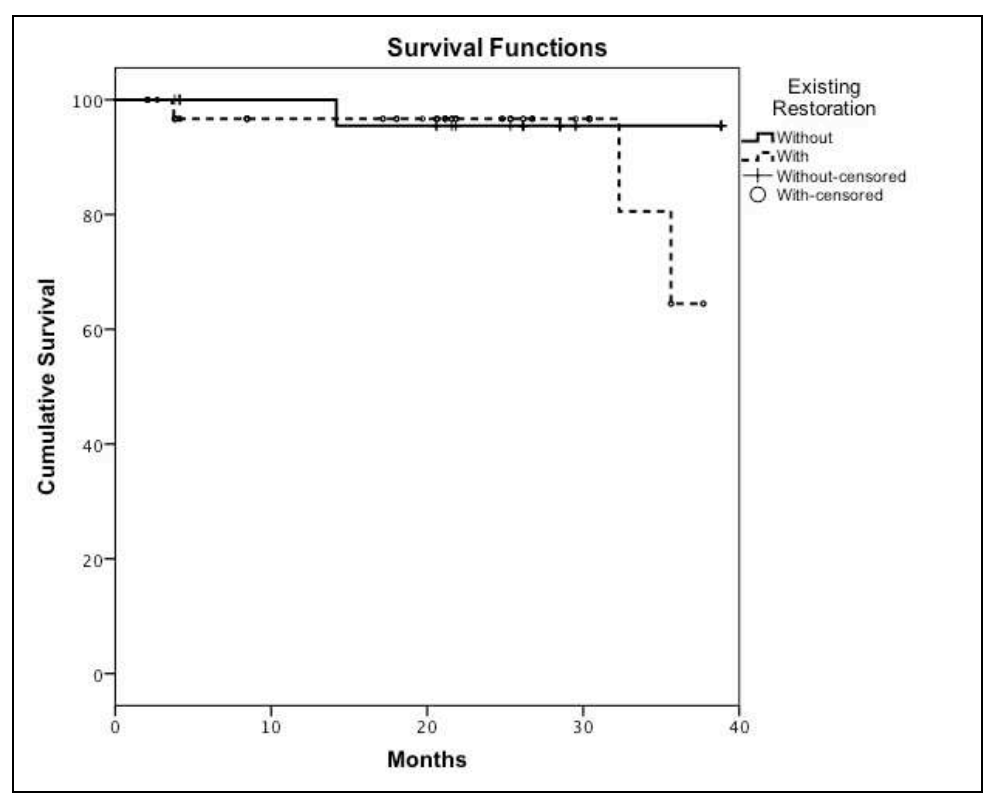

Fig. 1 Event-free survival rates of ceramic laminate veneers based on the substrate. They were bonded onto (intact tooth without composite restorations: $96.0 \% ; n=25$, events $n=1$; with existing restorations: $93.5 \% ; n=62$, events $n=4$ ). 

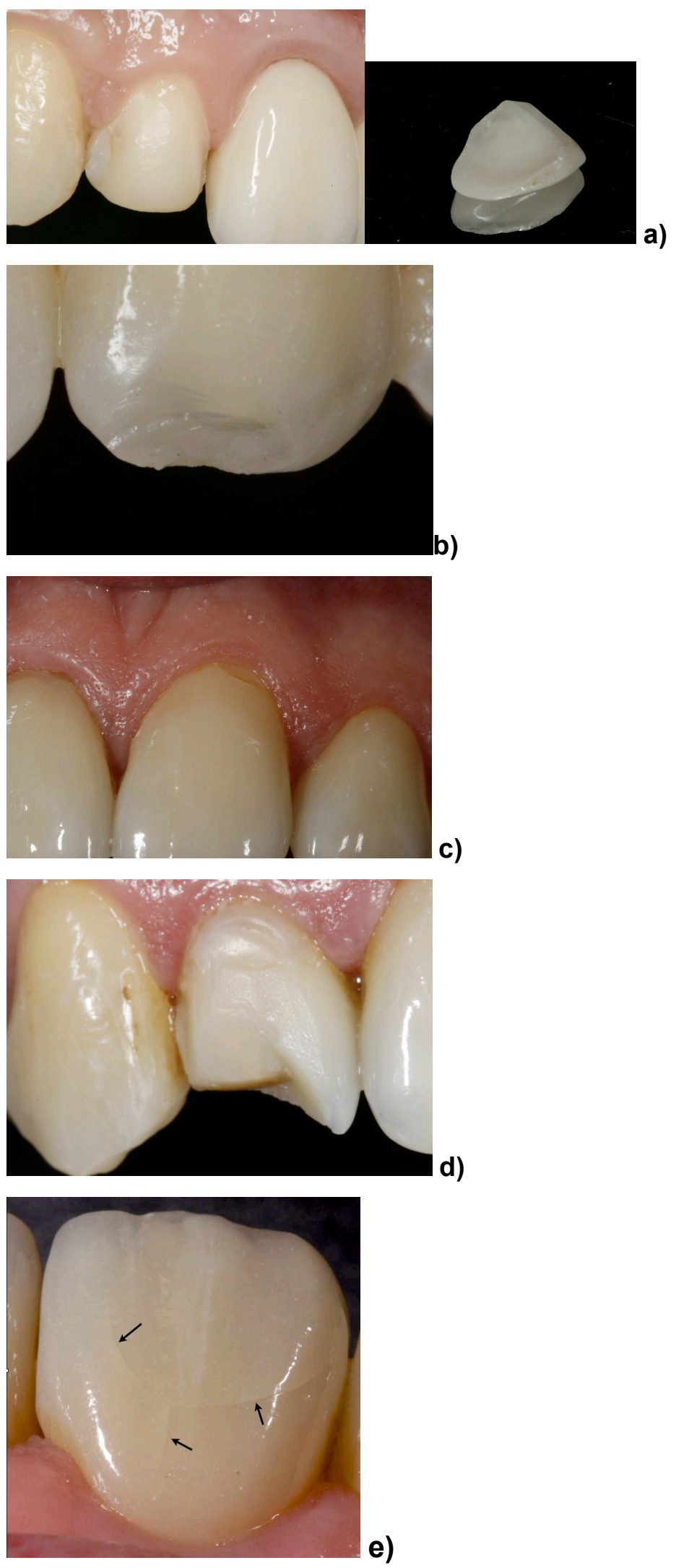
Figs 2a-e Representative photos of some failures a) adhesively debonded laminate from tooth 12 . Note that no resin cement was bonded on the tooth that had small existing resin composites on mesial and distal sides, b) cohesive chipping of the laminate at the incisal edge of the ceramic on tooth 23 that was bonded to tooth only, c) cervical fractures of the laminate veneer on tooth 21. It was bonded to big existing composite restorations on the mesial and distal sides of the tooth. The detached fragment was adhesively debonded with no resin cement bonded on the tooth, d) fracture of the laminate veneer on tooth 12 due to trauma that failed adhesively between the tooth and the luting cement and partially cohesively within the ceramic. Part of the ceramic laminate was left adhered where an existing composite was present and the other part was debonded from the dentin surface, e) multiple cracklines visible before fracture on laminate veneer bonded to tooth 11 without any existing restorations 